Tropical Journal of Pharmaceutical Research December 2016; 15 (12): 2709-2712

ISSN: $1596-5996$ (print); 1596-9827 (electronic)

(C) Pharmacotherapy Group, Faculty of Pharmacy, University of Benin, Benin City, 300001 Nigeria.

All rights reserved.

Available online at http://www.tjpr.org

Original Research Article

http://dx.doi.org/10.4314/tjpr.v15i12.24

\title{
Epidemiological studies on cutaneous leishmaniasis in Ad- Dawadimi District, Saudi Arabia
}

\author{
Abdullah D Alanazi ${ }^{1}$, Mohamed S Alyousif ${ }^{2 \star}$, Muheet A Saifi ${ }^{2}$, Ibrahim 0 \\ Alanazi $i^{3}$ \\ ${ }^{1}$ Department of Biological Sciences, Faculty of Sciences and Humanities, Shaqra University, PO Box 1040 Ad-Dawadimi \\ 11911, ${ }^{2}$ Department of Zoology, College of Science, King Saud University, PO Box 2455, Riyadh 11451, ${ }^{3}$ Genomic Center, \\ King Abdulaziz for Science and Technology, PO Box 6086, Riyadh 11442, Saudi Arabia
}

*For correspondence: Email: msaifi@ksu.edu.sa; Tel: +966114675777

Received: 22 April 2016

Revised accepted: 4 November 2016

\begin{abstract}
Purpose: To assess the prevalence of cutaneous leishmaniasis (CL) in Ad-Dawadimi region of Saudi Arabia.

Methods: Data from the patients included in this retrospective study were collected from the Leishmaniasis Control Center of Ad-Dawadimi District of Saudi Arabia. A total of 370 patients with CL were recorded from January 2009 to December 2013. The data focused on details of sociodemographics, i.e., age, gender, date of diagnosis, residence and close family members with CL.

Results: Out of 370 patients with verified lesions, 280 (75.6\%) were males with a mean age of $18.26 \pm$ 13.41 years, while 90 (24.3\%) were females with a mean age of $19.25 \pm 16.10$ years. The highest proportion (18.3\%) occurred in the 15 - 20 years age group. Annual distribution of CL showed that the highest rate was in 2010 with 168 cases while the lowest rate was in 2012 with 42 cases. There were no significant differences in the mean ages of the CL cases with respect to gender.

Conclusion: Most of the reported cases had with single facial lesions. Although all age groups are affected by CL, a majority of the cases are aged 15 to 30 years.
\end{abstract}

Keywords: Cutaneous leishmania, Epidemiology, Facial lesion, Age-related

Tropical Journal of Pharmaceutical Research is indexed by Science Citation Index (SciSearch), Scopus, International Pharmaceutical Abstract, Chemical Abstracts, Embase, Index Copernicus, EBSCO, African Index Medicus, JournalSeek, Journal Citation Reports/Science Edition, Directory of Open Access Journals (DOAJ), African Journal Online, Bioline International, Open-J-Gate and Pharmacy Abstracts

\section{INTRODUCTION}

Leishmaniasis is a complex disease of various clinical manifestations caused by infection with the protozoan parasites Leishmania spp. It is transmitted through bites from infected sand flies (Phlebotomus or Lutzomyia spp). Globally, there are an estimated $1.5-2$ million new cases and 70000 deaths each year, and 350 million people are at risk of infection by the disease. Leishmaniasis-induced morbidity and mortality cause an estimated 2.4 million disability-adjusted life years [1].
Cutaneous leishmaniasis is endemic in the Eastern Province of Saudi Arabia, mainly in the Al-Hassa Oasis. The vector of the disease in Saudi Arabia is the sand fly and the alternative natural hosts are desert rodents. Leishmania tropica, the causative agent of cutaneous leishmaniasis in the Al-Hassa Oasis, classically causes skin lesions without dissemination. The main vector for $L$. tropica is Phlebotomus sergenti [2].

The present study was aimed at determining the prevalence of cutaneous leishmaniasis in AdDawadimi region of Saudi Arabia. 


\section{EXPERIMENTAL}

\section{Study site}

Ad-Dawadimi is located on top of Najd Hill in the central area of Saudi Arabia. It is about $280 \mathrm{~km}$ west of Riyadh, the capital city of Saudi Arabia and is geographically located at latitude $24^{\circ}$ North and longitude $44^{\circ}$ East. The population of Ad-Dawadimi is approximately 240,000 thousand people. According to the Open Street Map project, Ad-Dawadimi has very hot summer up to $49^{\circ} \mathrm{C}$ or more with an average temperature of 44 ${ }^{\circ} \mathrm{C}$. Winter is very cold with temperature of $15^{\circ} \mathrm{C}$ and windy nights. The overall climate is arid, receiving very little rainfall of $21.4 \mathrm{~mm}$ with relative humidity ranging from 12 to $50 \%$ throughout the year.

\section{Data collection}

The data used in this retrospective study were from the Leishmaniasis Control Center of AdDawadimi district. The Center was established in 2009. A total of 370 patients with CL were recorded from January 2009 to December 2013. Suspected cases of $\mathrm{CL}$ are referred from the primary health center to the specialized clinic where clinical examination and laboratory investigations were carried out. Samples were further examined microscopically at the central laboratory of Leishmania Control Unit (Directorate of Health, Ad Dawadimi).

The case investigation form included details of socio-demographics such as age, gender, nationality, date of diagnosis, residence and referral health center. Clinical data included methods of diagnosis (clinical examination and microscopic examination), localization of the lesions and treatment received (type, dose, route and duration). Consent was taken from the hospital authority as well as parents. School authority permitted and parents agreed for given research while written permission was also taken from the institutional ethical committee and the studies followed international guidelines [3]

\section{Statistical analysis}

Data analyses were performed using SPSS software version 16.0, for Windows, (Sydney, Australia), as well as Students t-test.

\section{RESULTS}

In all, data from 370 patients with lesions were collected. Data analysis showed that $75.6 \%$ of patients were male (with a mean age of $18.26 \pm$
13.41 years), whereas 90 (24.3\%) patients were female (with a mean age of $19.25 \pm 16.10$ years). There were no significant differences in mean ages with respect to (Table 1). The youngest patient was 6 months of age and the oldest was 72 years. The mean age was $19.25 \pm 14.77$ years. The annual distribution of the cases showed that the highest incidence was in 2010 with 168 cases, and the lowest was in 2012 with 42 cases. The highest yearly incidence of $\mathrm{CL}$ was 1.68 per 10000 in 2010 and the lowest was 0.42 per 10000 in 2012 (Figure 1). CL cases showed seasonal variations. The incidence steadily began to increase in October, peaked in February, and decreased to minimum in July August (Figure 2).

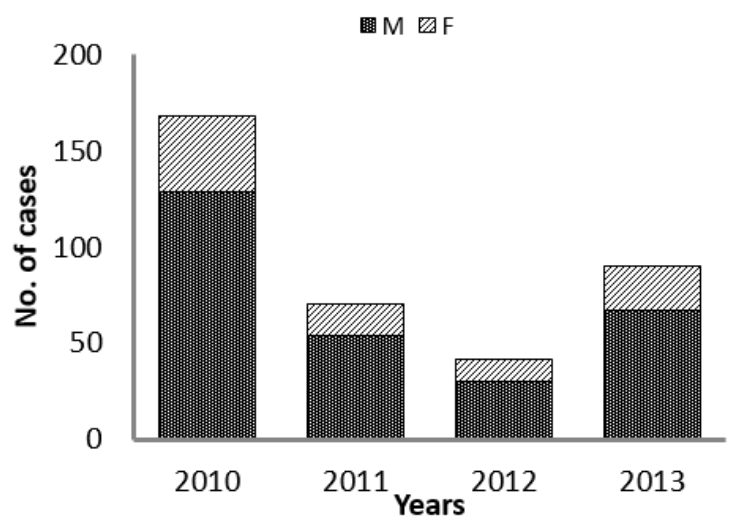

Figure 1: Ad-Dawadimi City location in Riyadh Province, Saudi Arabia

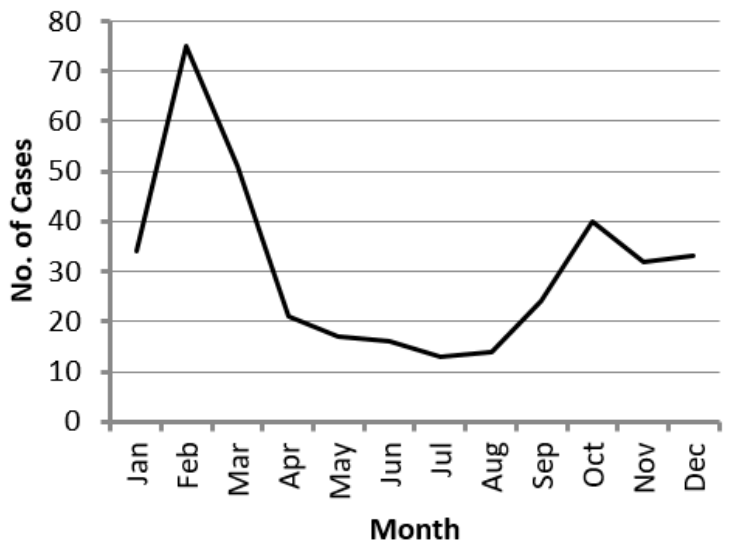

Figure 2: Monthly number of $\mathrm{CL}$ cases in $\mathrm{Ad}$ Dawadimi

A total of $292(78.9 \%)$ patients had one lesion; 39 patients $(10.5 \%)$ had 2 lesions while 19, 14 and 6 patients had 3, 4 and more than 5 lesions respectively (Table 2). CL was located mostly on the exposed parts of the body such as face (197, $53.2 \%)$; upper limb (109, $29.4 \%)$ and lower limb $(64,17.2 \%)$.

Trop J Pharm Res, December 2016; 15(12): 2710 
Table 1: Age and gender distribution of CL patients

\begin{tabular}{lccc}
\hline Age group (years) & Male (\%) & Female (\%) & Total (N) \\
\hline $0-5$ & $21(75)$ & $7(25)$ & 28 \\
$6-10$ & $43(84.3)$ & $8(15.6)$ & 51 \\
$11-15$ & $50(73.5)$ & $18(26.4)$ & 68 \\
$16-20$ & $39(81.2)$ & $9(18.7)$ & 48 \\
$21-25$ & $17(68)$ & $8(32)$ & 25 \\
$26-30$ & $26(76.4)$ & $8(23.5)$ & 34 \\
$31-40$ & $38(77.5)$ & $11(22.4)$ & 49 \\
$41-50$ & $17(68)$ & $8(32)$ & 25 \\
$50 \leq$ & $29(69)$ & $13(31)$ & 42 \\
Total & $280(75.6)$ & $90(24.5)$ & 370 \\
\hline
\end{tabular}

Table 2: Number of lesions per CL patient

\begin{tabular}{lcc}
\hline $\begin{array}{l}\text { No. of } \\
\text { lesions }\end{array}$ & $\begin{array}{c}\text { No. of } \\
\text { patients }\end{array}$ & $\%$ \\
\hline 1 & 292 & 78.9 \\
2 & 39 & 10.5 \\
3 & 19 & 5.1 \\
4 & 14 & 3.7 \\
$\geq 5$ & 6 & 1.6 \\
\hline
\end{tabular}

\section{DISCUSSION}

The purpose of this study was to assess epidemiological data of reported $\mathrm{CL}$ cases in Leishmaniasis Control Center of Ad-Dawadimi district Saudi Arabia. CL is a parasitic disease caused by the protozoa of the genus Leishmania such as L. tropica, L. major, L. aethiopica, and sometimes $L$. donovani and $L$. infantum. The infection is transmitted through small phlebotomine sand flies when they bite infected human or animal hosts. Clinical characteristics of leishmaniases depend on Leishmania parasite invasiveness, tropism, pathogenicity, and immune responses of the host [4-6]. Majority of the CL cases presented with single facial lesions. These finding are similar to those of Al-Tawfiq and Abu Khamsin [7]. Most recent epidemiological studies in Yemen, Saudi Arabia and Israel revealed a similar trend, with single lesions on the face or limbs being the most common form of presentation [7,9-12].

Al-Tawfiq and Abu Khamsin [7] had conducted a very comprehensive 46-year study on Leishmania cases in Saudi Arabia. They showed that CL had a very high incidence, almost reaching epidemic proportions in 1973 and thereafter declining to a plateau in the mid1980s. The results of this study confirm the downward trend in incidence of $\mathrm{CL}$, showing a clear decline especially during the period 20102014. A similar downward trend for the incidence was studied by Amin et al [2].

The seasonal incidence of CL seen in this study is similar to that of a previous study [2], which reported that the incidence increased in September and reached a peak in January/February. This might be related to the activity of the vector. In general, CL tended to affect the younger age group in most endemic areas. In two previous studies [2,4-7], majority of the cases occurred in people aged less than 15 20 years. This is similar to findings in other studies [10,13,14]. Although all age groups were affected by CL, majority of them were between 15-30 years old. The reason for low CL incidence among elderly patients may be related to the fact that they were infected during early ages and so acquired long-term immunity. Another factor is that older people do not care to visit a health center for the treatment of CL. Although they know about this disease, its disfiguring scars does not seem to bother them as much as it bothers youngsters. In addition, young people are more involved in outdoor activities which expose them more to the disease than older age groups. In our the present study, the lesions were found most frequently on the face; this is consistent with reports by Şanlıurfa and Adana $[15,16]$.

\section{CONCLUSION}

Majority of the reported cases of CL are those with single facial lesions. Although all age groups are affected by CL, most of the cases lie in the 15 - 30 years age group. There were no significant differences among the age groups with respect to gender.

\section{DECLARATIONS}

\section{Acknowledgement}

This project was kindly supported by Shaqra University, Deanship of Scientific Research. The authors would like to thank the staff members of Biological Sciences Department, Faculty of 
Sciences and Humanities, Shaqra University for technical support.

\section{Conflict of Interest}

No conflict of interest associated with this work.

\section{Contribution of Authors}

The authors declare that this work was done by the authors named in this article and all liabilities pertaining to claims relating to the content of this article will be borne by them.

\section{Open Access}

This is an Open Access article that uses a funding model which does not charge readers or their institutions for access and distributed under the terms of the Creative Commons Attribution License (http://creativecommons.org/ licenses/by/4.0) and the Budapest Open Access Initiative (http://www.budapestopenaccessinitiati ve.org/read), which permit unrestricted use, distribution, and reproduction in any medium, provided the original work is properly credited.

\section{REFERENCES}

1. Reithinger $R$, Dujardin JC, Louzir H, Pirmez $C$, Alexander $B$, Brooker S. Cutaneous leishmaniasis. Lancet Infect Dis 2007; 7(9): 581-596.

2. Amin TT, Kaliyadan F, Al-Ajyan MI, Al-Arfaj AK, AlMujhim MA, Al-Harbi SJ, et al. Public awareness and attitudes towards cutaneous leishmaniasis in an endemic region in Saudi Arabia. J Eur Acad Dermatol Venereol 2012; 26(12): 1544-1551.

3. International Ethical Guidelines for Biomedical Research Involving Human Subjects. Hinsdale (IL): CIOMS, Inc.; c2002 [cited 2013 Jan 5]. Available from http://www.cioms.ch/publications/layout_guide2002.p df

4. Uzun S, Durdu M, Çulha $G$, Allahverdiyev AM, Memişoğlu HR. Clinical features, epidemiology, and efficacy and safety of intralesional antimony treatment of cutaneous leishmaniasis: recent experience in Turkey. $J$ Parasitol 2004; 90: 853-859.

5. Uzun S, Uslular C, Yücel A, Acar MA, Özpoyraz M, Memişoğlu HR. Cutaneous leishmaniasis: evaluation of 3074 cases in the Çukurova region of Turkey $\mathrm{Br} J$ Dermatol 1999; 140: 347-350.
6. Gürel MS, Ulukanlıgil $M$, Özbilge $H$. Cutaneous leishmaniasis in Şanlıurfa: Epidemiologic and clinical features of the last four years (1997-2000). Int $J$ Dermatol 2002; 41: 32-37.

7. Al-Tawfiq JA, AbuKhamsin A. Cutaneous leishmaniasis: a 46- year study of the epidemiology and clinical features in Saudi Arabia (1956-2002). Int J Infect Dis 2004; 8(4): 244-250.

8. Mimouni D, Balicer RD, Levine H, Klement E, Bar-Zeev $Y$, Davidovitch $N$, et al. Trends in the epidemiology of cutaneous leishmaniasis in a young adult population in Israel: a long-term survey. Int J Dermatol 2009; 48(6): 611-613.

9. Khatri ML, Di Muccio T, Gramiccia M. Cutaneous leishmaniasis in North-Western Yemen: a clinicoepidemiologic study and Leishmania species identification by polymerase chain reaction restriction fragment length polymorphism analysis. J Am Acad Dermatol 2009; 61(4): e15-21.

10. Bamba S, Gouba A, Drabo KM, Nezien D, Bougoum M, Guiguemdé TR. Trends in incidence of cutaneous leishmaniasis from 1999 to 2005 in Ouagadougou, Burkina. Med Trop (Mars) 2011; 71(3): 312.

11. Farahmand $M$, Nahrevanian $H$, Shirazi $H A$, Naeimi $S$, Farzanehnejad Z. An overview of a diagnostic and epidemiologic reappraisal of cutaneous leishmaniasis in Iran. Braz J Infect Dis 2011; 15(1): 17-21.

12. Bousslimi N, Aoun K, Ben-Abda I, Ben-Alaya-Bouafif N, Raouane M, Bouratbine A. Epidemiologic and clinical features of cutaneous leishmaniasis in southeastern Tunisia. Am J Trop Med Hyg 2010; 83(5): 1034-1039.

13. Fendri $A H$, Beldjoudi $W$, Ahraou $S$, Djaballah $M$. Leishmaniasis in Constantine (Algeria): review of five years (2006-2010) at the University Hospital. Bull Soc Pathol Exot 2012; 105(1): 46-48.

14. Morrone A, Pitidis A, Pajno MC, Dassoni F, Latini O, Barnabas GA, et al. Epidemiological and geographical aspects of leishmaniasis in Tigray, northern Ethiopia: a retrospective analysis of medical records, 2005-2008. Trans R Soc Trop Med Hyg 2011; 105(5): 273-280.

15. Douba M, Mowakeh A, Wali A. Current status of cutaneous leishmaniasis in Aleppo, Syrian Arab Republic. Bull World Health Organ 1997; 75: 253- 259.

16. Mohebali M, Javadian E, Yaghoobi-Ershadi MR, Akhavan $A A$, Hajjaran $H$, Abaei MR. Characterization of Leishmania infection in rodents from endemic areas of the Islamic Republic of Iran. East Mediterr Health $J$ 2004; 10(4-5):591-9. 